www.periodicos.unimontes.br/index.php/caminhosdahistoria

\title{
ATITUDE MUDA: O GRUPO UM, A PRODUÇÃO MUSICAL INDEPENDENTE E O LIRA PAULISTANA (1976 - 1984)
}

\author{
Renan Branco Ruiz ${ }^{1}$
}

Recebido em: 24/04/2020

Aprovado em: 09/06/2020

Resumo: A partir de entrevistas com os gestores da carreira do Grupo Um (jazz brasileiro instrumental), este artigo analisa as ações empreendidas pela banda no cenário de transformações da indústria fonográfica brasileira da virada dos anos 1970. Tendo como principal objetivo analisar as contribuições do Grupo Um para a formação da produção musical independente, que emergia nessas décadas, o propósito foi refletir sobre os modos de atuação da banda frente ao novo dinamismo do mercado brasileiro de gravações musicais. Dentre as hipóteses formuladas, destaca-se a relação de intensa proximidade que o jazz brasileiro e a música instrumental tiveram com o surgimento da Vanguarda Paulista e as ações do Lira Paulistana, tal vinculo é geralmente deixado de lado pela historiografia. Assim, a bibliografia sobre o assunto delegou um lugar coadjuvante e secundário as composições de caráter instrumental e jazzístico, cerne da sonoridade não só do Grupo Um, como de outras bandas de fusion brasileiro desse período (Divina Increnca, Pé ante Pé, Metalurgia, Medusa, entre outras). Essa relação se constituiu sobre uma base de tensões com o universo da canção (composições com letra e canto), que também ficou mais alinhado a ideia de Vanguarda Paulista. Tal termo foi criado pela imprensa e se consolidou como o elo para algumas transformações estéticas e experimentações que circulavam pelo Lira Paulistana (em São Paulo no início dos anos 1980) mesmo que a música instrumental e o jazz brasileiro estivessem umbilicalmente presentes nesse contexto.

Palavras-chave: Grupo Um; Vangurda Paulista; música instrumental; jazz; Lira Paulistana.

\section{ACTITUD MUDA: GRUPO UM, PRODUCCIÓN MUSICAL INDEPENDIENTE Y LIRA PAULISTANA (1976 - 1984)}

Resumen: Basado en entrevistas con los directores de carrera del Grupo Um (jazz instrumental brasileño), este artículo analiza las acciones emprendidas por la banda en el escenario de las transformaciones en la industria musical brasileña a principios de la década de 1970. Al presentar, como objetivo principal, analizar las contribuciones de Grupo Um para la formación de producción musical independiente, que surgió en estas décadas, la finalidad fue reflexionar sobre las formas de actuación de la banda frente al nuevo dinamismo del mercado de grabación de música brasileña. Entre las hipótesis formuladas, se destaca la relación de intensa proximidad que tuvo el jazz brasileño y la música instrumental con el surgimiento de Vanguarda Paulista y las acciones de Lira Paulistana, un vínculo que la

\footnotetext{
${ }^{1}$ Mestre e Doutorando em História pela Faculdade de Ciências Humanas e Sociais (FCHS). Universidade Estadual Paulista "Júlio de Mesquita Filho, UNESP, Franca-SP, Brasil. E-mail: renan.ruiz@unesp.br. ORCID: https://orcid.org/0000-0002-0778-8895. O presente artigo expõe alguns resultados da dissertação de mestrado: "Procura-se Mecenas": Música independente e indústria fonográfica na trajetória artística do Grupo Um (1976-1984) (UNESP, 2017), defendida pelo autor deste artigo, com financiamento da FAPESP, sob o processo $n^{\circ} 2015 / 09829-3$.
} 
historiografía generalmente pasa por alto. Así, la bibliografía sobre el tema delegó un lugar secundario a las composiciones instrumentales y jazzísticas, el núcleo del sonido no solo del Grupo Um, sino de otras bandas de fusión brasileñas de ese período (Divina Increnca, Pé ante Pé, Metalurgia, Medusa , entre otras). Esta relación se construyó sobre una base de tensiones con el universo de la canción (composiciones con letras y canto), que también se alineó más con la idea de Vanguarda Paulista. Este término fue creado por la prensa y se consolidó como el enlace para algunas transformaciones y experimentos estéticos que circularon a través de Lira Paulistana (en São Paulo a principios de la década de 1980) a pesar de que la música instrumental y el jazz brasileño estaban umbilicamente presentes en este contexto.

Palabras clave: Grupo Um; Vanguarda Paulista; música instrumental; Jazz; Lira Paulistana.

\title{
SPEECHLESS ATTITUDE: THE GRUPO UM, THE MUSICAL INDEPENDENT PRODUCTION AND THE LIRA PAULISTANA (1976 - 1984)
}

\begin{abstract}
Based on interviews with career managers of Grupo Um (instrumental Brazilian jazz), this article aims to study how the band performed in the transformation scenario of the Brazilian music industry at the turn of the 1970s. Having as its main objective to analyze the contributions of Grupo Um to the formation of the independent musical production that emerged in these decades, the purpose was to reflect on the group's ways of performing in face of the new dynamism of the market for Brazilian recorded music. Among the formulated hypothesis, the relationship of close proximity that Brazilian jazz and instrumental music had with the emergence of Vanguarda Paulista and the actions of Lira Paulistana stand out; such a connection is usually overlooked by historiography. Thus, most of the bibliography on the subject delegated a supporting and secondary place to instrumental and jazzy compositions, these being basically the core of sonority not only of Grupo Um, but of other Brazilian fusion bands of that period (Divina Increnca, Pé ante Pé, Metallurgy, Medusa, among others). This relationship was built on a base of tensions with the universe of the canção (compositions with lyrics and singing), which also became more aligned with the idea of Vanguarda Paulista. This term was created by the press and consolidated itself as the link for some aesthetic transformations and experiments that circulated through Lira Paulistana (in São Paulo in the early 1980s) even though instrumental music and Brazilian jazz were umbilically present in that context.
\end{abstract}

Keywords: Grupo Um; Vanguarda Paulista; instrumental music; jazz; Lira Paulistana.

\section{Introdução}

O Grupo Um foi uma banda de jazz instrumental que atuou no mercado musical brasileiro entre 1976 - 1984. A gestão das obras da banda foi realizada pelos irmãos Zé Eduardo Nazário e Lelo Nazário, que além de suas diversas atividades no universo musical, focaram sua atuação artística nos trabalhos realizados pelo Grupo Um durante seu período de atividade. O conjunto foi formado quando os dois irmãos e o primeiro baixista do grupo, Zeca Assumpção, ainda faziam parte da banda de Hermeto Pascoal. Durante o período de atuação do Grupo Um, também participaram do conjunto o baixista Rodolfo Stroeter, o saxofonista e flautista Mauro Senise, o músico alemão Félix Wagner e os saxofonistas Teco Cardoso e Roberto Sion, além do percussionista Carlinhos Gonçalves. 
É justamente no final dos anos 1970 e início de 1980, que o discurso pautado pela ideia de música independente começa a ganhar força no Brasil, a partir da ampliação das referências a essa ideia na imprensa, da atuação dos selos Kuarup, Bemol, Som da Gente e Lira Paulistana, e das atividades próprias de alguns artistas e conjuntos (como Antonio Adolfo, Boca Livre, Luli e Lucinha, entre outros). Realizando a produção de seus discos independentemente de contratos com as gravadoras já estabelecidas, conseguiram não só gravar e lançar seus álbuns como também obter uma repercussão considerável na imprensa, a partir das fortes mudanças estruturais no mercado de música e na indústria fonográfica brasileira (VICENTE, 2014, p. 55-94).

Em matéria publicada no caderno Ilustrada do jornal Folha de São Paulo, no dia 12 de março de 1982, Lelo Nazário refere-se simbolicamente a um mecenas, utilizando-se ironicamente do distanciamento temporal dessa figura tradicional do financiador das artes no intuito de dar visibilidade à conjuntura enfrentada pelos instrumentistas do período. Segundo o anúncio: "Procura-se Mecenas. Músicos de reconhecido nível artístico e vasto currículo profissional procuram mecenas para financiar seu novo projeto. Tratar com Lelo Nazário, Tel: (011) 571-8541; Rodolfo Stroeter, Tel: (011) 65 - 5305”2 . O próprio Lelo ressalta, em 2016, que foi ele mesmo quem pagou para custear o anúncio, e foi caro. Ressaltou, também, que muitos jornalistas quiseram fazer uma matéria como se ele estivesse passando fome, mas ele tinha outros trabalhos, não era esse o ponto. O foco era chamar atenção para uma situação: aquela enfrentada não só pelo Grupo Um mas pela geração instrumental de jazz brasileiro (NAZÁRIO, 2016).

Assim, o principal fio condutor encontrado na trajetória do grupo manifesta-se justamente na "procura pelo mecenas", no sentido de que seus instrumentistas estiveram sempre buscando condições para financiar a gravação de suas obras, optando, assim, por um novo caminho produtivo que começava a ganhar força no período. As diversas dificuldades encontradas pelo Grupo Um também residem na ousadia do conjunto, cujas obras musicais possuem sonoridades distantes daquelas geralmente veiculadas pelas grandes companhias da indústria fonográfica brasileira.

Enfim, esse artigo analisa as contribuições do Grupo para formação da produção musical independente, que emergia em São Paulo (capital) final dos anos 1970 e início da década de 1980. Objetivando refletir sobre os modos de atuação da banda frente ao cenário fonográfico durante seu período de atuação (1976 - 1984), formulou-se um cenário

\footnotetext{
${ }^{2}$ Procura-se Mecenas. F. de São Paulo, São Paulo, 12 mar. 1982. Ilustrada, p. 33.
} 
elucidativo onde, apesar de uma intensa atividade musical relacionada não só ao Grupo Um como outras bandas de música instrumental e jazz brasileiro desse período(Divina Increnca, Pé ante Pé, Metalurgia, Medusa, entre outras), foi a música em formato canção (cantada) que se vinculou de forma íntima com a o termo Vanguarda Paulista. Tal relação interfere diretamente nos mecanismos de mediação ${ }^{3}$ e inteligibilidade social do Grupo Um e sua geração, que estavam muito próximos do Lira Paulistana, mas não são mencionados nas produções acadêmicas e rememorações sobre a música paulistana de caráter experimental que circulava nesse âmbito.

É importante ressaltar que este trabalho não intenta "defender" o Grupo Um perante a ideia de Vanguarda Paulista e/ou sua aproximação com o Lira Paulistana, muito menos busca incluí-los em determinado rótulo criado pela imprensa. O objetivo é apenas contribuir com o debate sobre esse momento recente e complexo da história da música nacional, sobre como o passado é (re)construído a partir de diversas narrativas simbólicas em choque. Nessas disputas, o jazz brasileiro e a música popular instrumental foram relegados, até o momento, do seu lugar essencial para a produção musical independente e para potencialização das ações e musicalidades experimentais que circulavam pelo Lira Paulistana e na Vanguarda Paulista, em São Paulo no início dos anos 1980.

Em relação as entrevistas, foram realizadas em junho - julho de 2016 e concedidas para elaboração da pesquisa de mestrado, onde estão publicadas (RUIZ, 2017). A proposta foi realizar uma comparação entre as percepções dos músicos e irmãos Zé Eduardo Nazário (entrevistado via por e-mail) e Lelo Nazário (entrevistado presencialmente). Como veremos adiante, suas concepções não estão, necessariamente, alinhadas. Também é nosso intuito verificar como se constrói a interpretação da relação do conjunto com o Centro de Promoções Artísticas Lira Paulistana e com a ideia de Vanguarda Paulista, na rememoração dos músicos

\footnotetext{
${ }^{3}$ A ideia de mediação é utilizada neste trabalho a partir das considerações de Raymond Williams (1979, 2011, 2015) e Theodor W. Adorno (2011a, 2011b, 2012). Apesar de discordarem em diversos pontos na construção de suas teorias sobre a sociedade e a cultura (inclusive na própria conceituação deste último), ambos analisaram os processos de tensionamentos entre arte e sociedade que a produz e consome. Os dois autores convergem sobre a constituição de um processo complexo de inter-relação tensionada e negociada entre a possibilidade de formação de determinado conteúdo artístico e as particularidades do meio histórico e social do período em que é produzido. Para ambos, linguagem artística e a sociedade que a circunscreve não se articulam segundo hierarquias previamente definidas de enfrentamento e relação, mas são faces de um mesmo processo desigualmente disputado em cada local e momento histórico específico. Mesmo com muitas diferenças na concepção teórica de Adorno e Williams, existe uma aproximação latente entre os dois autores (como diferentes formas de da superação da relação ortodoxa que se estabeleceu por um período entre base $x$ superestrutura da teoria marxista) no sentido de enxergar a forma artística (musical, no caso de Adorno e literária, no caso de Williams) como resultado e matéria-prima, ao mesmo tempo, dos processos da sociedade que a compõe, sendo, portanto, mediadas.
} 
e de alguns dos gestores do Lira - Wilson Souto Júnior, Chico Pardal (ambos entrevistados pessoalmente) e Riba de Castro (via e-mail).

Quando perguntados sobre sua trajetória pessoal, artistas e pessoas públicas em geral tendem a superestimar suas próprias ações ao recordar-se das etapas vivenciadas. Assim, reitero que a utilização dos depoimentos está inscrita na ordem das reflexões sobre as muitas construções imaginativas do passado e não como imagens do que "realmente aconteceu". Conforme demonstra Jacy Seixas (2002, p. 45) “a memória não é estática, nem seu volume e conteúdo são fixos; ela se movimenta, e esse movimento configura um espiral no espaço e no tempo, que se inicia e se atualiza no presente", dessa forma "a memória não é regressiva (algo que parte do presente fixando-se no passado); ela é prospectiva e, mais do que isso, é projetiva, lançando-se em direção ao futuro". Outras indicações de Jacy Seixas (2001) e Ulpiano Menezes (1992) serviram de arcabouço para análise das entrevistas orais e sua relação com a memória.

Não obstante, é importante deixar claro que este trabalho não compreende nem se utiliza das fontes memoriais dos entrevistados enquanto representações fiéis do acontecido, nem imagina que tais depoimentos possam conter a verdade sobre a trajetória do conjunto ou mesmo acerca desse período estudado. Apenas entendo que a restituição do passado feita pelos agentes envolvidos nas atividades da banda constitui uma rica esfera documental por denotar a subjetividade dos indivíduos envolvidos na trajetória da banda. Por isso, pode ser utilizada como uma das muitas interpretações possíveis sobre a história do Grupo Um.

\section{A formação de um grupo de jazz instrumental brasileiro (1976-1979)}

O ano de $1976^{4}$ parece ser um divisor de águas nas carreiras de Zé Eduardo e Lelo Nazário. Enquanto ambos se apresentavam com o grupo de Hermeto Pascoal, surgia também a necessidade de criar um trabalho próprio, cujas características composicionais estivessem mais próximas de suas referências particulares. Sobre o assunto, Lelo Nazário comenta que "a música do Hermeto tem um sentido muito definido", pois captou a riqueza do ambiente nordestino e tensionou tais sonoridades com o desenvolvimento do jazz, deixando até mesmo os músicos norte-americanos surpreendidos, pois era jazz, "mas era diferente, era um outro negócio”. Lelo ressalta: “Agora, eu nasci em São Paulo, né? Eu tinha uma outra visão, eu tinha estudado a música erudita, a música eletroacústica, que eu adorava. (...) Eu adorava

\footnotetext{
${ }^{4}$ Vale ressaltar que nesse ano a indústria fonográfica brasileira atinge um grandioso nível de crescimento e ampliação do mercado: a taxa de crescimento foi de 46\%, segundo a pesquisa: VICENTE, 2014, p. 50-51.
} 
tocar com ele, claro, mas não era a minha coisa, sabe? Você vê uma outra coisa que te interessa mais e então, eu fui por aî” (NAZÁRIO, 2016, destaque nosso).

No resgate memorial feito pelos irmãos, é possível perceber que o pianista Lelo acaba ressaltando a vontade de criar um trabalho diferente do realizado com Hermeto, enquanto o baterista Zé Eduardo (2016), apesar de também afirmar que o grupo buscava uma identidade própria, indica a necessidade de sobrevivência como fator crucial. Abandonar o conjunto de Hermeto Pascoal parecia ser uma decisão difícil, já que, mesmo no início da década de 1970, o músico nordestino já era um ícone da música instrumental e do jazz no Brasil, tendo inclusive tocado ao lado do consagrado músico Miles Davis.

Sobre a importância de atuar no conjunto de Hermeto Pascoal, Zé Eduardo Nazário diz, em 1980, que abandonou uma possibilidade de trabalho nos EUA para ficar no Brasil ao lado do instrumentista nordestino e que durante sua experiência com Hermeto, vivenciou "uma faculdade de música mesmo (...) É um negócio que você tem um mestre que te orienta, não só na música mas na vida também" (NAZÁRIO, 1980). Mesmo com toda essa importância atribuída por Nazário ao trabalho junto de Hermeto Pascoal, após alguns anos ocorreu a saída do conjunto. Provavelmente, isso também está ligado à intensa proximidade sonora que os irmãos Nazário foram construindo desde cedo, até mesmo antes de trabalharem com Hermeto. Como afirma Lelo Nazário, a vontade de criar algo próprio existia mesmo antes da aproximação com o músico nordestino, pois, como dois irmãos músicos eles sempre ensaiavam e tocavam juntos, desde cedo.

Joaquim Carlos Pinto Nazário (Lelo) é o principal compositor do Grupo Um, responsável por onze das dezesseis músicas registradas nos três $L P S$ da banda. O músico também responde pela inserção das técnicas da música moderna (como música eletroacústica, por exemplo) nas obras do conjunto. Sua curiosidade pela gravação e edição de sons surgiu ainda menino, pois seu pai era diretor dos Diários Associados (conglomerado de mídia de Assis Chateaubriand), e Lelo brincava com diversas tipos de fitas e registros sonoros. É compositor, pianista e produtor musical, tendo estudado com professores particulares e de forma autodidata. Compôs obras orquestrais para a Banda Sinfônica do Estado de São Paulo, além de diversas trilhas.

Nascido em 1956, na capital paulista, Lelo foi convidado ainda muito jovem, com apenas 17 anos, para integrar o conjunto de Hermeto Pascoal, permanecendo até 1977 , quando saiu para lançar um projeto com suas próprias composições: o Grupo Um. Formou o Symetric Ensemble, Duo Nazário, e o trio Percussônica. Durante os anos 1990, fez parte do cultuado grupo Pau Brasil, gravando o importante disco Babel (1995) que, inclusive, ganhou 
o Prêmio Sharp na categoria "grupo instrumental", em 1998, além de ser indicado ao Grammy como melhor performance de jazz. Gravou cinco discos solo e montou seu estúdio próprio (Utopia) em 1980, onde trabalha até hoje, atuando em gravações, mixagens, masterização e recuperação de áudio.

José Eduardo Pinto Nazário nascido em 1952, São Paulo, já havia atuado profissionalmente no meio musical antes de trabalhar com seu irmão (pianista Lelo Nazário) e de tocar ao lado de Hermeto Pascoal. Já com treze anos, integrou o grupo de sambajazz Xangô 3 (1965-1968), no qual tocou ao lado de jovens músicos, inclusive Itiberê Zwarg. Montou o Grupo Experimental de Percussão de São Paulo, ao lado de Guilherme Franco, além de tocar em algumas casas noturnas da capital paulista, como o Toten e o Camja (Clube de Amigos do Jazz), onde entrou em contato com muitos músicos. Em 1972, formou o grupo Mandala, com Roberto Sion, Nelson Ayres e Luiz Roberto Oliveira, e, em 1974, o Malika, com seu irmão e Hector Costita.

Também nos anos 1970, além dos trabalhos com o Grupo Um e com Hermeto Pascoal, o baterista fez parte da banda de Egberto Gismonti, realizando a turnê Tropical Jazz Rock, ao lado de John McLaughin, no início de 1979. Nos anos 1990, Zé Eduardo Nazário também fez parte do aclamado conjunto Pau Brasil, por um período manteve quase a mesma formação do último disco do Grupo Um, A flor de plástico incinerada (1982), além dos irmãos Nazário, contou com Rodolfo Stroeter no baixo e Teco Cardoso nos sopros. Zé Eduardo também atua como professor de bateria desde os anos 1980 até hoje.

Para além das aspirações pessoais dos irmãos Nazário, a própria possibilidade de trabalhar com o viés jazzístico e instrumental de música está vinculada a um contexto muito específico de desenvolvimento desses gêneros musicais no Brasil dos anos 1970. Contribuíram para a estruturação dessa conjuntura os (1) festivais internacionais de jazz em São Paulo e Rio Janeiro (em $1978^{5}$ e 1980, com a presença de algumas figuras marcantes do fusion mundial, como John McLaughin, Chick Correa, Larry Coryell e George Duke), (2) a presença de Hermeto Pascoal, Egberto Gismonti e Airto Moreira no contexto internacional, e algumas iniciativas fonográficas, como a série de discos (3) MPBC e o projeto Trindade (MULLER, 2005, p. 47-52), entre outros aspectos.

\footnotetext{
${ }^{5} \mathrm{O}$ evento aconteceu entre os dias onze e dezoito de setembro, com diversas atrações nacionais e internacionais no Palácio de Convenções do Anhembi e contou com um público de mais de sessenta mil pessoas. O festival foi organizado pela Secretaria Municipal da Cultura da cidade de São Paulo, em parceria com a Rádio e TV Cultura, que fizeram a transmissão ao vivo do festival. Figuras muito importantes para o desenvolvimento do fusion mundial marcaram presença no festival.
} 
Em 1977, já definitivamente distanciado do trabalho com Hermeto Pascoal, o Grupo Um realiza a gravação de seu primeiro registro como conjunto e leva o material até algumas gravadoras, no intuito de conseguir viabilizar algum acordo de prensagem e distribuição. Essa busca pelo apoio das majors, nesse momento da trajetória do conjunto, demonstra que o caminho de produção musical independente ainda não era uma perspectiva considerada como totalmente viável. O material foi gravado no estúdio Vice-Versa, de Rogério Duprat, mas o apoio para prensagem e lançamento não se concretizou.

Lelo Nazário (2016) recorda que apesar do material ter superado a expectativa de seus instrumentistas "a gente não conseguiu lançar. Pretendíamos lançar por uma gravadora, né? Aquele velho caminho. (...) Era um material que não interessava. Música instrumental, ainda mais avançada assim. A gente foi continuando, e esse material ficou meio parado". Uma passagem interessante do depoimento de Lelo é a utilização da expressão "velho caminho" para caracterizar o ato de busca por gravadoras para lançamento de obras musicais, denotando um viés considerado tradicional no campo fonográfico. A ideia de que a música instrumental é uma vertente deixada de lado pelos produtores de discos também fica caracterizada por sua resposta. Sobre o material, seu irmão Zé Nazário (2016) ressalta que "nenhuma gravadora tinha coragem de lançar materiais como aquele que tocávamos, uma música totalmente inovadora e diferente". Dessa forma, o único meio para se inserir no mercado foi arcar com todos os custos de produção, segundo o baterista, "só assim pudemos colocar na praça nossa música".

$\mathrm{Na}$ entrevista, Lelo Nazário responde que chegaram a enviar esse material, provavelmente, para a Som Livre, a EMI-Odeon, a Continental e a Warner. É interessante o fato de a Continental figurar na lista, pois quando, no ano de 1982, o Grupo Um gravou e lançou A flor de plástico incinerada, seu único disco feito em parceria com algum outro tipo de empreendimento que não o dos próprios instrumentistas, o fez no contrato estabelecido com o selo Lira Paulistana Instrumental, já em fase de parceria com a Continental. Em entrevista concedida a Aramis Millarch em 1980, o baterista Zé Eduardo Nazário comenta que levaram essa fita até Guto Graça Melo, da Som Livre, mas que recebeu um bilhete dizendo que o material era ótimo mas não interessava, "e a gente tem o bilhetinho guardado até hoje. Foi através do Márcio Montarroyos que eu levei a fita ao Rio de Janeiro. [...] Alguns nem recebiam a gente. Faziam a gente ir até lá, ficava esperando, e nem recebiam a gente".

É claro que a recusa por parte das grandes gravadoras também se alicerça no fato de a música instrumental produzida pelo Grupo Um ser um tanto quanto diferenciada dos padrões estéticos estabelecidos, que se tornariam cada vez mais homogêneos a partir, justamente, 
desse momento histórico. Todavia, esse acontecimento em 1977 pode ser visto como uma imagem bastante elucidadora da conjuntura vivida pelos instrumentistas nesse momento particular do mercado de música no Brasil. Isso acontece porque, na década de 1970, o universo fonográfico brasileiro cresceu como nunca antes, estruturando um cenário deveras específico de expansão das bases produtivas e de racionalização tanto dos métodos de trabalho quanto dos artistas e a formação de seu repertório (DIAS, 2000, p. 56-95).

Esse movimento realizado pela indústria do disco na década de 1970 é vinculado a um contexto mais abrangente de reforma artística e cultural no Brasil. Conforme indicado de maneira pontual por Renato Ortiz, o governo militar brasileiro (1964-1985), a partir da ideia de "segurança nacional", realizou uma intensa reforma nas indústrias de base, investindo nas tecnologias de comunicação, com o objetivo de integrar o Brasil, e fornecendo toda a estrutura necessária para a inserção das transnacionais do setor fonográfico no país. Os anos 1960 e 1970 são caracterizados, segundo ele, pela "consolidação do mercado de bens culturais": a amplitude social de produtos artísticos atinge níveis massivos pela primeira vez na dinâmica nacional, a partir da reorganização econômica gestada pelo governo militar e da racionalização dos métodos de produção de bens artísticos (ORTIZ, 1988, p. 113 -148).

Além do mercado fonográfico, também o editorial, o cinematográfico e o de telenovelas, entre outros, atingem níveis de expansão surpreendentes, estabelecendo, no país, uma dinâmica massificadora de consumo (NAPOLITANO, 2001b, p. 82). Cada diferente esfera técnica de linguagem artística (teatro, música, cinema, literatura, etc.) respondeu de maneira própria ao alargamento das bases produtivas (NAPOLITANO, 2001a, p. 104). O setor fonográfico é um dos principais expoentes dessa ampliação de bens culturais na sociedade. Sua expansão é baseada em algumas práticas centrais dos modos de operação das majors no Brasil: a forte veiculação da música estrangeira no Brasil, incentivada logo após AI-5 (1968) (MORELLI, 2009, p. 62), a definição do elepê como formato usual para distribuição física (DIAS, 2000, p. 60-61) e a consolidação da MPB enquanto gênero de mercado.

Dessa forma, a principal estratégia de atuação da nossa moderna indústria fonográfica em expansão no início dos anos 1970 foi o privilégio aos artistas estrangeiros. Em um segundo momento, o setor focou suas atenções em determinados artistas brasileiros, cada vez mais consagrados pela mídia e considerados os representantes da MPB, que ia, assim, se estabelecendo como instituição (NAPOLITANO, 2001). Isto é, apesar do intenso desenvolvimento das bases produtivas e do constante aumento do mercado consumidor de discos, cresce, também, o número de artistas que não conseguiam atuar profissionalmente a 
partir de contratos e parcerias com as empresas fonográficas já instituídas no país. Assim, o final dos anos 1970 é o momento de uma intensa ampliação da ideia de música e/ou produção musical independente no Brasil, com a emergência (WILLIAMS, 1979, p. 116-129) ${ }^{6}$ de novas possibilidades de inserção de material gravado no mercado nacional. É interessante notar como, nesse contexto, o ano de 1977 (momento da "última tentativa" do Grupo Um na busca sistemática pelo apoio de uma grande gravadora) é significativo e ilustra bem esse período de transição de velhos hábitos fonográficos para novos caminhos de produção musical que ganhavam força exatamente nesse mesmo período.

O momento da reorganização do cenário fonográfico brasileiro e da articulação entre os modos de ação das majors e as novas formas de atuação na gestão da música gravada (que foram denominadas independentes) é um aspecto vinculado ao alinhamento da dinâmica nacional à organização global do mercado fonográfico, característica do processo de mundialização da cultura (DIAS, 2000, p. 43-49). A forte concentração de empresas é um dos traços mais marcantes da dinâmica geral da indústria fonográfica mundial. Durante todo o século XX, o agrupamento dos empreendimentos de produção sonora em formato de conglomerados empresariais foi uma constante, e foi paulatinamente ganhando força.

No Brasil, a década de 1970 é o momento de intensificação desse processo, que culmina com o fechamento das últimas empresas de capital nacional, já nos anos 1990, ao serem compradas por algumas transnacionais em ascensão (DIAS, 2000, p. 46-47). Essa interrelação entre os mercados nacional e mundial de discos é um fenômeno característico do rearranjo cultural e artístico experimentado a partir dos efeitos da chamada mundialização da cultura (nos termos de Márcia Tosta Dias e Renato Ortiz (1994)), globalização (conforme apresentada por Octavio Ianni (2005)), ou mesmo uma característica do pós-modernismo ou da lógica cultural do capitalismo tardio, na linha das reflexões de Fredric Jameson (1997).

Para além das várias diferenças existentes entre as concepções desses autores, parece ser possível apontar um fio condutor comum a todas elas: a constituição de uma nova configuração das sociedades (principalmente ocidentais) a partir do avanço do mercado internacional (em uma nova fase do capitalismo), e a massificação das novas tecnologias

\footnotetext{
${ }^{6}$ A ideia de pratica cultural emergente é pensada a partir das indicações de Raymond Williams (1979, p 124129). Segundo o autor, ela se dá sempre em relação aos aspectos residuais e dominantes de determinada esfera de produção cultural. A proposta é ressaltar que os elementos hegemônicos em determinado âmbito social e cultural não são nunca totais ou abarcam todas as possibilidades de significação, pelo contrário: estão sempre em contato e disputa com outras formas interpretativas, mesmo que de alcance limitado. Nesse sentido, a produção musical independente parece se configurar como um elemento emergente no mercado brasileiro de música gravada, com um substancial número de bandas e artistas recorrendo à esse meio na virada dos anos 1970 .
} 
comunicacionais e de entretenimento, que passam a estruturar e mediar cada vez mais as novas formas de relação social, em profunda transformação a partir de meados dos anos 1950.

Vale ressaltar, aqui, as intensas problemáticas inerentes à própria ideia de música independente: o conceito é escorregadio e duvidoso, haja vista as distintas possibilidades existentes para a inserção de artistas nos diferentes momentos de organização da indústria fonográfica brasileira, desde seu nascimento, no início do século XX. A expressão também é um tanto quanto problemática pois pode acabar simplificando as variadas configurações de mediação às quais uma obra está sujeita em determinado período. No entanto, sua utilização neste artigo se ancora justamente nesses deslizes e indefinições, no intuito de pensar e refletir as variadas táticas, formas e possibilidades de inserção de determinado material musical no mercado fonográfico brasileiro.

Também é importante lembrar que, conforme demonstra Igor Garcia de Castro (2010, p. 66-81), atitudes e ações consideradas como independentes em relação à grande indústria do disco existem desde o nascimento da indústria fonográfica no Brasil, nas primeiras décadas do século XX. O autor demonstra a pluralidade de projetos marginais existentes no país, indo desde o projeto Disco Popular, criado ainda na década de 1910, até as revoluções digitais dos anos 1990 em diante, passando pela série de Cornélio Pires, nos anos 1920, pela gravadora Elenco, vinculada à Bossa Nova, nos anos 50, e pelo boom da produção musical independente na virada dos anos 1970.

No período que vai do final dos anos 1970 ao início dos 1980, há um momento bastante particular de ampliação da retórica independente no universo musical, devido ao grande avanço produtivo do setor fonográfico sem, no entanto, uma ampliação concomitante do leque de artistas e estéticas presentes no mercado musical. Assim, essa ideia ganhou força e uma quantidade maior de artistas passaram a se utilizar tanto do discurso da independência musical, quanto das práticas de produção alternativas. Conforme lembra Gil Nuno Vaz (1988, p. 18) o interessante é perceber que, historicamente, a atitude independente passa de algo incomum para algo em comum. Deixa de ser "algo inusitado" para se tornar uma "solução viável”, a partir da segunda metade dos anos 1970. Além disso, conforme afirma Márcia Tosta Dias, o universo de produção musical independente, pode parecer alheio a dinâmica das majors, mas, na verdade, se altera de acordo com ela, em uma relação complementar, "mesmo que indireta e aparentemente conflituosa" (DIAS, 2000, p. 129).

Vale registrar que Lelo Nazário foi convidado a redigir dois textos sobre a ideia de arte independente alguns anos depois, em 1982 (um em março e outro em setembro). Naquele momento, sua opinião é categórica, salientando que os discos independentes do seu período 
"vem acompanhada de uma grande mistificação e distorção do conceito de independência" pois "reproduz valores estéticos estabelecidos e será facilmente absorvida"7 . Assim, é possível perceber que o Grupo Um também se apropriou dessa ideia de independência musical, até mesmo de forma "romantizada", como a exposta no artigo de Lelo em 1982. Pois, como lembra Gil Nuno Vaz (1988, p. 18), “passava a ser fator de destaque e de prestígio ostentar o rótulo de independente". Wilson Souto Júnior, idealizador e principal gestor do Centro de Promoções Artísticas Lira Paulistana discorre sobre o termo independente, segundo ele, começou “com Boca Livre. Que depois estourou como independente. Mas essa ideia acalmou e depois voltou com o Lira" (SOUTO JR; PARDAL, 2016).

A partir dessas reflexões, é importante destacar, finalmente, a relevância da experiência do disco gravado e não lançado em 1977 como uma espécie de incentivo para o Grupo Um buscar e encontrar novas saídas para viabilizar o registro e a distribuição de seu trabalho. Os irmãos Nazário relembram que após não conseguirem estabelecer nenhum tipo de parceria em 1977, já estavam "achando que não ia dar certo". Nesse sentido, se deparar com o viés independente de produção parece ter fornecido uma solução necessária e definitiva. Outra questão importância destacada pelos irmãos é a relevância dada ao músico Antônio Adolfo, figura que ficou reconhecida por "dar o start" nas produções independentes na virada da década de 1970 , incentivando outros grupos a fazerem o mesmo ${ }^{8}$. Lelo Nazário (2016) diz na entrevista que chegou a ligar para Antônio, no intuito de conhecer mais sobre os meandros desse novo caminho produtivo.

Enfim, podemos perceber que a própria possibilidade de constituição social do Grupo Um esta inevitavelmente articulada tanto à conjuntura bastante particular do jazz (principalmente vinculada à ideia de fusion) e da música instrumental no Brasil do final dos anos 1970, quanto à ascensão da ideia de música independente (no mesmo período) que, a partir das condições severas de uma indústria fonográfica em ascensão na quantidade de vendas, mas com uma concomitante redução no cast de artistas, ampliou sua força enquanto retórica e criou um cenário que incentivava novas saídas para produção musical.

\footnotetext{
${ }^{7}$ NAZÁRIO, Lelo. A mistificação do disco independente. F. de São Paulo, São Paulo, 21 mar. 1982. Ilustrada, p. 58. Grifos meus.

${ }^{8}$ Algumas pesquisas já indicavam a presença de Antonio Adolfo e a criação do seu selo Artezanal, em 1977, como um importante marco para a história da música independente no país. Isso acontece porque, após sua atitude, houve uma ampliação muito grande de produções independentes no país, iniciando uma movimentação no final dos anos 1970 e início de 1980. Antonio Adolfo conseguiu respaldo da imprensa e sua ação ficou consideravelmente reconhecida, funcionando como um incentivo para a geração que se formava naquele momento. O depoimento de Lelo Nazário corrobora com essa perspectiva. Sobre a referência a Antonio Adolfo, ver: VICENTE, 2014, p. 124; VAZ. 1988, p. 13 e DIAS. 2000, p. 136.
} 
Conforme apontou Fenerick (2007, p. 31): “a produção 'independente' de música no início dos anos 80, apresentava caminhos diferenciados e apontava para uma solução, se não a ideal, ao menos factível para o lançamento de novos trabalhos e artistas no mercado musical brasileiro". Nesse primeiro momento da trajetória do grupo, é possível perceber que a falta de um material lançado no mercado fonográfico determina o cenário de suas possibilidades, pois os nomes de seus integrantes ainda eram quase que exclusivamente vinculados às suas participações nos conjuntos de outros músicos importantes do jazz e da música popular instrumental brasileira.

\section{A produção independente como solução (1979-1984)}

Após as tentativas de inserção no mundo fonográfico tradicional em 1977, o Grupo Um passou a procurar, paulatinamente, outras possibilidades para o registro de seu material. Assim, em 1979, o Grupo Um viabiliza, às próprias custas, a gravação e a prensagem em elepê do primeiro registro lançado do conjunto, Marcha sobre a cidade, disco que abriu muitas portas para a carreira da banda e foi o responsável pela aproximação desses músicos das ações e atividades do Centro de Promoções Artísticas Lira Paulistana 9 .

O estúdio Vice-Versa, do maestro Rogério Duprat, já era utilizado pelo conjunto antes da gravação de Marcha sobre a cidade. O material de 1977 também foi gravado por lá. O grupo também fez trilhas nesse mesmo estúdio e chegou a ensaiar nesse espaço quando tocavam com Hermeto Pascoal. O ano de 1979 também é particularmente interessante para o movimento realizado na dinâmica da música gravada no Brasil: ele marca o final de um longo processo de altíssimo crescimento pelo qual o setor passava desde o final dos anos 1960. Conforme aponta Eduardo Vicente, as taxas de crescimento da produção da indústria fonográfica brasileira foram, desde 1966 e até 1979, “invariavelmente positivas”(VICENTE, 2014, p. 50). Márcia Tosta Dias (2000, p. 81), na mesma linha, aponta que a indústria fonográfica brasileira atingiu, em 1979, "número recorde de 64.104 milhões de unidades vendidas, dos quais 23.480 milhões eram de música estrangeira e 40.624 milhões, nacional”, mesmo no cenário de crise econômica do período final do governo civil-militar.

\footnotetext{
${ }^{9}$ O álbum Marcha sobre a cidade foi gravado nos dias 26 e 27 de setembro de 1979 e prensado no mesmo ano com tiragem inicial de mil cópias. A edição original, em elepê, conta com seis faixas, três em cada lado. Participaram da gravação, além dos irmãos Zé Eduardo e Lelo Nazário, o baixista Zeca Assumpção, o saxofonista e flautista Mauro Senise e o percussionista Carlinhos Gonçalves. Na reedição no formato de Compact Disc, em 2002, duas faixas bônus foram adicionadas, oriundas das gravações do disco não lançado de 1977.
} 
Marcha sobre a cidade é gravado justamente nesse ano marcante, em que a indústria fonográfica brasileira alcançou patamares de vendas e circulação de obras musicais nunca antes alcançados. Não por coincidência, é quando o Grupo Um, sem conseguir um espaço nas instituídas empresas de discos, conclui a gravação de seu primeiro trabalho lançado no mercado. O resgate memorial dos irmãos Nazário e de alguns setores musicais, consideram esse disco como o primeiro elepê independente de música instrumental na história do Brasil. Logicamente, esse resgate intenta cristalizar o lugar do Grupo Um frente à história do jazz, da música popular instrumental brasileira e da ideia de música independente. Para além dessa possível classificação generalizadora, nossa intenção é refletir sobre como o álbum ficou marcado justamente por possibilitar a ascensão do grupo e iniciar uma série de elepês independentes que saíram no mercado no início da década de 1980, mesmo num momento de crise da indústria do disco. Além disso, com o álbum, a parceria com o Centro de Promoções Artísticas Lira Paulistana se cristalizou, iniciando, também, uma espécie de cena de jazz. instrumental que se articulava em torno do Lira, com a participação de outros nomes desse viés musical, como o Divina Increnca, Pau Brasil, Pé-Ante-Pé, Freelarmônica, Medusa, entre outros.

Assim, o Grupo Um encontrou um importante meio para vazão de seu trabalho a partir da aproximação com o Lira Paulistana, palco de diversos empreendimentos sonoros singulares na história da música paulistana. Essa aproximação aconteceu “por acaso", já que o local de ensaio do conjunto - em um estúdio próprio na casa de Zé Eduardo Nazário - era muito perto do Centro de Promoções Artísticas Lira Paulistana. Segundo mostram os relatos, a proposta de lançamento de Marcha sobre a cidade, por parte de Zé Eduardo, parece ter sido realizada antes mesmo da inauguração do espaço (que aconteceu em outubro de 1979), haja vista que ele morava muito perto do teatro e se encontraram por acaso, enquanto pintavam o local, antes do espaço ficar pronto para eventos artísticos. Segundo Lelo (2016) "não tinha nada ainda programado quando Zé Nazário propôs tocar ali. Assim que o teatro terminou, o Gordo [Wilson Souto Jr] avisou que estava disponível pra fazer, então foi bem no começo mesmo".

A importância do lançamento de Marcha sobre a cidade (gravado em setembro de 1979) para a convergência de trajetórias do próprio Grupo Um e do Centro de Promoções Artísticas Lira Paulistana (que abriu as portas em outubro de 1979) parece ser indubitável. Isso porque o momento de aproximação entre essas duas empreitadas se dá justamente no começo da montagem da programação e da própria existência do Lira, e no início da segunda 
etapa da carreira do Grupo Um, em que finalmente foi viabilizado o primeiro trabalho prensado em vinil e disponível para lançamento.

A temporada de lançamento de Marcha sobre a cidade aconteceu no Lira Paulistana em fevereiro de 1980, no começo de sua atuação como produtores. Um fator determinante para a organização do espaço durante seu período de atividade foi justamente o imprevisto e a falta de racionalidade empresarial (principalmente no primeiro momento, de 1980 à 1982). Em outras pesquisas, foi possível constatar que o nível de planejamento do Lira Paulistana era mínimo, no início e em boa parte do decorrer de suas atividades: Wilson Souto Júnior (gordo) procurava um lugar onde pudesse fazer um estacionamento de dia e peças de teatro à noite (GHEZZI, 2003, p. 112-113). A programação do espaço, bem como sua inserção no mercado fonográfico através de vias alternativas, foi feita de acordo com as novas opções que surgiram após a abertura do espaço artístico, sem planejamento prévio.

No depoimento cedido a mim em junho de 2016, Wilson Souto Júnior faz afirmações parecidas: "cara, pra mim foi assim: a gente abriu a porta e simplesmente veio essa onda de música instrumental. Veio todo mundo, na verdade. E o instrumental também muito forte. Na verdade, aconteceu". Ao que tudo indica, essa "onda instrumental" à qual se refere Wilson surgiu pela primeira vez, para o empresário, justamente nessa conversa informal que teve com Zé Eduardo Nazário, ainda antes da abertura do espaço, no final de 1979. É interessante notar que em outros momentos, como no ano de 1981, em entrevista à revista Veja, Wilson Souto Júnior faz um comentário diferente, atribuindo a si mesmo a ideia de um projeto previamente estipulado e organizado: "Minha ideia era capitalizar a explosão criativa dessa nova vanguarda, criando um espaço para se produzir espetáculos e ideias, agindo na infraestrutura" ${ }^{\prime 10}$. É claro que seu depoimento, nesse contexto, está totalmente vinculado a conjuntura daquele período, buscando dar mais publicidade ao seu empreendimento em uma revista de grande circulação.

Haja vista que o teatro abriu as portas em outubro de 1979, é possível perceber que a temporada de lançamento de Marcha sobre a cidade, em fevereiro de 1980, foi importante para o andamento das atividades do teatro relacionadas ao jazz e à música instrumental. Isso acontece porque tais apresentações aconteceram justamente nesse período inicial das atividades do Centro de Promoções Artísticas Lira Paulistana, em que o nível de previsibilidade e racionalidade empresarial ainda eram mínimos. Aliás, boa parte da programação do Lira ainda não havia sido formada, e graças ao lançamento de Marcha sobre

\footnotetext{
${ }^{10}$ SOUZA, Okky de. Uma turma de ideias. Revista Veja, São Paulo, n. 681, set. 1981, p. 120.
} 
a cidade o espaço começou a organizar sua própria agenda. Além disso, ao que tudo indica, foi a partir dessa temporada que outros grupos de música instrumental se aproximaram do Lira, construindo uma relação que culminaria na criação de um selo voltado exclusivamente para os grupos instrumentais do período. Em uma matéria no jornal Folha de São Paulo, no caderno Ilustrada do dia 27 de julho de 1980, o próprio título já demonstra o vínculo que se criou entre o Lira Paulistana e a música instrumental de São Paulo: "No Lira, palco aberto para o som instrumental":

Quando o Teatro Lira Paulistana foi aberto em outubro do ano passado, a ideia era criar um espaço cultural independente do centro da cidade. Inaugurado com uma peça inédita de um grupo novo, "Fogo Paulista", $o$ teatro programou nos últimos meses diversos conjuntos de música instrumental que ainda não possuem discos gravados. [...] o Teatro Lira Paulistana apresenta instrumentistas cujos trabalhos, pela qualidade e pela novidade, vêm sendo apontados pelo público como de vanguarda. [...] E sempre às segundas e terças, dentro de um novo projeto chamado "Música entre Amigos". [...] Com isso, a música instrumental acabou ocupando quase que integralmente a programação do Lira Paulistana. ${ }^{11}$

Em fevereiro de 1980 aconteceu uma das primeira apresentações de alguma banda no teatro, já em julho do mesmo ano, um jornal tradicional e de grande circulação já publica uma matéria como essa, destacando a presença quase que integral da música instrumental na programação do espaço. O texto destaca também o projeto "Música com os amigos", encabeçado por Zé Eduardo Nazário, a partir dos cursos de bateria que lecionava no espaço do Lira. Dessa forma, é possível perceber que o nível de inserção da música instrumental de cunho jazzístico no Centro de Promoções Artísticas Lira Paulistana foi consideravelmente alto, e a aproximação entre ambos bastante precoce. É, também, a partir dessa aproximação que se inicia o processo de aumento da visibilidade do Lira em várias esferas, inclusive em alguns periódicos de grande circulação.

O acordo para o lançamento de Marcha sobre a cidade previa, em um primeiro momento, a realização de cinco apresentações em fevereiro de 1980. Contudo, conforme o andamento dos shows e o aumento da popularidade do Lira e do reconhecimento do trabalho do Grupo Um, foram realizados quinze concertos no mesmo mês. A possibilidade de apresentação via temporadas, em que o artista se apresenta em vários dias seguidos no mesmo local, é uma característica marcante da programação do Lira. Sobre essa forma de atuação em apresentações musicais, Wilson Souto Júnior comenta: "Porque essa experiência de fazer temporadas era impressionante, era diferente. Porque hoje você vê uma apresentação apenas

\footnotetext{
${ }^{11}$ NO LIRA, palco aberto para o som instrumental. F. de São Paulo, São Paulo, 27 jul. 1980. Ilustrada, p. 47. Grifos meus.
} 
na cidade e sabe-se lá quando vai acontecer de novo o mesmo artista. Isso de fazer temporadas era um diferencial".

Dessa forma, percebemos que a temporada de lançamento de Marcha sobre a cidade, em fevereiro de 1980, foi um marco no itinerário percorrido tanto pelas produções do Lira Paulistana quanto pelo Grupo Um. Após esses concertos, o conjunto conseguiu visibilidade e meios para viabilizar apresentações em outros locais da cidade. Em março, se apresentaram no SESCafé, projeto do SESC, e em abril no Museu de Arte de São Paulo (MASP). A temporada inicial, no Lira Paulistana, proporcionou repercussão na mídia impressa, com algumas matérias e artigos, tendo sido divulgada na seção de apresentações do jornal Folha de São Paulo por quase todo o mês de fevereiro. Diversas matérias citando as apresentações de Marcha Sobre a Cidade no Lira foram realizadas em 1980 e 1981, entre elas no jornal $A$ Tribuna $^{12}$, Jornal do Brasil, revista Manchete ${ }^{13}$, Movimento ${ }^{14}$,Estadão e Folha de São Paulo. Todas elas elogiando demasiadamente as características do Grupo Um, sua performance e sonoridade desafiadora.

Os irmãos Nazário, apesar de trabalharem juntos na construção da carreira do Grupo Um, interpretam de formas bastante diferentes a aproximação do trabalho do conjunto com o Centro de Promoções Artísticas Lira Paulistana e a própria relevância do empreendimento cultural para a cena de jazz instrumental de São Paulo e para a trajetória do grupo. Lelo reconhece a importância do espaço, enquanto Zé Eduardo (2016) chega a dizer até mesmo que "O Lira não teve importância nenhuma". O tom das rememorações de cada um dos irmãos Nazário é bastante diferente nesse quesito.

Vale lembrar, esse segundo momento da banda coincide com os anos finais da ditadura civil-militar brasileira (1964 -1985). Apesar da atmosfera de recomeço que paira sobre esse período e que corroborou com o clima contracultural (que da vazão à produção musical independente e circunscreve a ambientação social do Grupo Um), é importante frisar: a censura musical nunca demonstrou muita preocupação com os artistas do viés instrumental, justamente pela não execução do texto vocal cantado. Inclusive, é durante a década de 1970 que existe uma espécie de revival do choro (SIGNORI, 2009,p. 14), primeiro nicho de música popular instrumental reconhecida como autenticamente brasileira.

Além disso, ao contrário do que se imagina e conforme foi demonstrado na pesquisa de Carrocha (2007, p. 75 -78), a censura musical (engendrada pelo Departamento de Censura

\footnotetext{
${ }^{12}$ RIENZI, Francisco Teixeira. Rumo ao Grupo Um. A Tribuna, Santos, 28 fev. 1980.

${ }^{13}$ MUGGIATI, Roberto. Mauro Senise e o Grupo Um. Revista Manchete, Rio de Janeiro, abr. 1980.

${ }^{14}$ JAZZ: A volta do Grupo Um. Movimento, São Paulo, 5 out. 1981. Cultura.
} 
de Diversões Públicas, DCDP, criado em 1966 e pelo Conselho Superior de Censura, em 1978) não fica mais branda no período reconhecido como abertura política, a partir de 1974 (com Geisel) ou 1979 (com Figueiredo), mantendo sua atuação até 1985. É a censura a imprensa que diminui sua atuação nesse período final da ditadura. Assim, no contexto final do regime militar, é a crise econômica, principalmente pós 1980 (NAPOLITANO, 2014, p. 153; 304-305), que interfere de forma mais latente na sobrevivência do Grupo Um enquanto atuante no mercado, mesmo que localizado na produção independente.

Nesse cenário, é necessário ressaltar: a geração de instrumentistas da virada dos anos 1970 que se alinhou às temáticas que giravam em torno da ideia de música independente é constituída por vários músicos que acompanhavam cantores da época. A série de discos MPBC, da major Phonogram, é um exemplo claro desse cenário: é a partir desse empreendimento que muitos músicos tiveram a possibilidade de registrar e lançar, pela primeira vez, suas próprias obras musicais no mercado brasileiro, apesar de sua ampla atuação anterior no setor fonográfico, na qual, no entanto, acompanhavam cantores. Nelson Ayres, Djalma Correa, Stenio Mendes, Robertinho Silva e Luis Claudio Ramos são exemplos dessa situação.

Assim, a ideia de produção musical independente, no viés instrumental, ganha um sentido bastante específico a partir dessa disputa com a hegemonia do formato canção (cantado). Está em jogo, aí, sua própria possibilidade de existência, desvinculada dos cantores. As novas representações do nacional-popular e/ou do nacionalismo musical e seu caráter estruturante na canção, também influenciam a lógica de funcionamento do campo instrumental nesse contexto de tensões com universo da música cantada. Isso se dá na tentativa de encontrar formas de utilizar, na música, elementos facilmente considerados nacionais, para além do uso das palavras, da letra, do canto e da entoação.

A revista Veja comenta, sobre o Grupo Um:

Há pelo menos dois grupos que rompem com a tradição maçante e repetitiva da música sem canto que se faz no país. O mais atrevido deles é o Grupo Um, que incorpora influências do compositor Schoenberg e dos jazzistas modernos numa formidável babilônia sonora altamente instigante. Sua música não respeita padrões ou limites; são exercícios diletantes sobre o ruído e a forma, sobre linhas melódicas pulverizadas pela dissonância. Naturalmente, em conjunto, tudo faz sentido, criando uma espécie de trilha sonora para momentos de inquietude (SOUZA, p. 120).

Apesar das dificuldades, podemos considerar que a distribuição de Marcha sobre a cidade foi bastante eficaz: isso porque todos os mil elepês da primeira prensagem se esgotaram ainda em 1980. A partir do contato próximo que se estabeleceu entre os 
instrumentistas do Grupo Um e os membros do Centro de Promoções Artísticas Lira Paulistana, foi realizada uma segunda prensagem, agora custeada pelos gestores do espaço artístico.

Dessa forma, a produção independente como um caminho para a gestão musical parecia extremamente viável para o conjunto. Após o lançamento às próprias custas de Marcha sobre a cidade, da aproximação com o Teatro Lira Paulistana (entre outros locais de apresentação, como o MASP, o SESC e a FUNARTE) e de uma inserção considerável em periódicos impressos, o Grupo Um conseguiu, finalmente, não só viabilizar o registro físico de seu trabalho, as apresentações de lançamento e os concertos em outras cidades (Rio de Janeiro, Distrito Federal e Paraná são os primeiros estados fora de São Paulo visitados pelo grupo), como também esgotar a primeira prensagem e estabelecer uma parceria para a segunda tiragem de discos. Dessa forma, a opção do conjunto foi continuar os ensaios e as composições, até que, em 1981, o segundo álbum (Reflexões sobre a crise do desejo) foi preparado, gravado e lançado ${ }^{15}$.

Se em 1977 o Grupo Um iniciou sua tentativa de inserção no universo da música gravada a partir da busca por parcerias com gravadoras estabelecidas tradicionalmente no Brasil, em 1982 um acordo entre o selo Lira Paulistana e a Continental (uma das últimas grandes gravadoras brasileiras) geraria bastante expectativa para seus instrumentistas, e também para outros artistas e pessoas envolvidas com a área musical no período. Assim, nesse terceiro momento do grupo (1982-1984) aconteceu a tão sonhada parceria para gravação e distribuição de seu material sonoro, para a realização do trabalho intitulado $A$ flor de plástico incinerada. A experiência parece ter sido um tanto quanto frustrante no quesito distribuição, e veio acompanhada de um novo momento na trajetória dos músicos, em que a atenção e o tempo disponíveis para trabalhar no projeto do Grupo Um foram sendo, aos poucos, redirecionados.

No cenário de crise na produção de discos, nos primeiros anos de 1980, o novo contrato do Lira era visto com empolgação, até mesmo nos jornais da época, conforme demostra a matéria intitulada "Muitos discos do Lira, uma ótima notícia", publicada em 27 de

\footnotetext{
${ }^{15}$ Vale ressaltar neste momento que, paralelamente ao trabalho do Grupo Um, Zé Eduardo também realizou, no Lira Paulistana, em 1980, um longo curso de bateria que culminava em jam sessions entre o próprio Zé, seus alunos e instrumentistas de jazz do período convidados pelo baterista do Grupo Um. Zé Eduardo lecionava aulas de bateria e percussão desde essa época em sua casa (inclusive, seu primeiro aluno foi Azael Rodrigues, primeiro baterista do conjunto Pau Brasil e responsável percussivo pelo grupo Divina Increnca), quando teve a ideia de fazer esse curso, que se repetiu em 1983 e que também chegou a ser bastante divulgado em jornais de grande circulação do período. Tal curso e as apresentações derivadas dele, que aconteciam às segundas e terças, também colaboraram para criar um clima para a música instrumental no Lira. Vários instrumentistas conheceram o espaço através dessas apresentações organizadas por Zé Eduardo.
} 
dezembro de 1982 no jornal Folha de São Paulo, "a maior novidade do próximo ano será a produção associada do Lira Paulistana com a Continental. (...) Já em janeiro desembocam nas lojas, resultados do convênio Lira /Continental, os discos do grupo Paranga, o solo de Zé Eduardo Nazário e o Grupo Um" "16. O artigo demonstra o referido entusiasmo. O ano de 1983 começava com uma nova parceria discográfica que traria ao mercado musical uma ampliação dos trabalhos de "qualidade", considerados esteticamente ousados pela crítica. No excerto, é interessante a perspectiva de como o convênio entre o Lira e a Continental forjavam, para o autor, uma espécie de arma contra a padronização do grande mercado.

Ghezzi demonstra, em seu trabalho, que a distribuição do material musical (grande problema da produção independente) acabou não correspondendo às expectativas geradas em praticamente todos os artistas envolvidos nesse contrato. Wilson Souto Júnior, mediador do processo, representante das bandas e principal responsável pela parceria, comenta no mesmo sentido. É importante destacar que esse momento de convergência entre o Lira e a Continental (que, não por acaso, coincide com a crise na indústria do disco) também demonstra uma nova estratégia que seria cada vez mais recorrente na relação entre as majors e as produções independentes: o da prospecção de novos artistas, mirando aqueles já amplamente testados por iniciativas independentes antes de apostarem em sua incursão pelas grandes gravadoras (DIAS, 2000, p. 127-129).

A partir dos anos 1970, com a segmentação do mercado fonográfico se consolidando de forma estrutural no Brasil e a multiplicação de gêneros e estilos pensados a partir de determinados nichos sociais, esse procedimento de testagem de artistas e grupos em início de carreira se cristalizou enquanto estratégia de fôlego para as grandes empresas. Ou seja, esse empreendimento entre o selo independente Lira Paulistana e a major Continental é uma expressão para novos horizontes de vendas e pela busca de novos artistas ante os problemas da economia brasileira no final da ditadura civil-militar e, mais especificamente, a crise do setor fonográfico.

Sobre tal parceria entre o Lira e a Continental, o discurso de diversos dos envolvidos parece ser uníssono: grandes expectativas em um primeiro momento e frustração logo em seguida. A possibilidade de conseguir um financiamento para gravação e lançamento de material foi, como pudemos perceber, um acontecimento inédito na trajetória do Grupo Um, realizado apenas no terceiro e último álbum de estúdio. Apesar da conquista, esse momento já se identifica com a fase final do conjunto, caracterizado por poucas apresentações e por um

\footnotetext{
${ }^{16}$ ALMEIDA, Miguel. Muitos discos do Lira, uma ótima notícia. F. de São Paulo, São Paulo, 27 dez. 1982. Ilustrada, p. 17. Grifos meus.
} 
maior foco de seus integrantes em projetos paralelos do que no próprio trabalho do Grupo Um. Pelo material que foi encontrado em minha pesquisa sobre o histórico de apresentações do conjunto (onde fui auxiliado pelo próprio Lelo Nazário), foi possível constatar um baixo nível de atividade a partir de 1982. Naquele ano, antes da gravação de A flor de plástico incinerada, realizada em outubro de 1982, o Grupo Um se apresentou apenas no MASP e no Centro Cultural São Paulo (CCSP). No mesmo ano, após a gravação, o conjunto realizou somente mais um concerto, na Bahia.

Sobre o ano de 1983, há um dado curioso: o conjunto quase não realizou nenhuma apresentação. Houve apenas uma única turnê, na Europa, na qual foram realizadas concertos na França e na Suíça. Assim, esse terceiro momento, em que um inédito contrato fonográfico foi estabelecido e uma turnê fora do país foi realizada, é curiosamente acompanhado do final dos trabalhos do Grupo Um. Nos releases em sites e documentos que se referem ao conjunto, inclusive os dos próprios integrantes, o ano de 1984 é registrado como o último em que a banda esteve em atividade. No entanto, segundo minha pesquisa, nenhuma ação vinculada ao conjunto foi realizada durante esse ano.

No contrato estabelecido com o selo Lira/Continental, também estavam incluídos a gravação e o lançamento do primeiro álbum solo de Zé Eduardo Nazário (Poema de Gota Serena, 1982) e o também primeiro de Lelo Nazário (Lágrima/ Sursolide Suite, 1982). A possibilidade de trabalhar profissionalmente no mercado musical com o próprio nome (produzindo o trabalho de estreia já com o apoio de um selo independente em parceria com um nome de peso das grandes empresas da música) foi, naturalmente, um dos elementos que acabou ampliando as atividades musicais e o escopo de atuação dos gestores da carreira artística do Grupo Um, fornecendo novos caminhos pessoais e mais particulares de trabalho.

\section{Considerações finais}

O que intentei fazer neste artigo foi refletir sobre os modos de atuação do Grupo Um frente ao novo dinamismo e às transformações do mercado e da indústria fonográfica brasileira na virada da década de 1970. A partir das entrevistas coletadas exclusivamente para este estudo e daquela de 1980, encontrada por mim no Acervo Aramis Millarch, foi possível se aventurar nas armadilhas da memória e analisar o modo como os agentes envolvidos nesse processo recente da música nacional interpretam (ou interpretavam) as atividades relacionadas ao curto período de atuação do Grupo Um. 
Se até o ano de 1977 o conjunto buscava sua inserção no mercado de música gravada a partir de caminhos tradicionais, ou seja, pela busca por gravadoras consolidadas no cenário brasileiro, é possível identificar que a própria possibilidade de existência do Grupo Um é mediada por novos caminhos para a produção musical, que ganharam força no período e cujas ideias ficaram reconhecidas sob a grande retórica generalizadora de música e/ou produção musical independente. A partir do contato que estabeleceram com essa ideia, os músicos puderam encontrar meios para viabilizar o lançamento de seus três trabalhos concretizados (em 1979, 1981 e 1982). A atuação do grupo, também está intrinsecamente vinculada à expansão, nesse mesmo período, das propostas musicais instrumentais de cunho jazzístico (e sua aproximação com a retórica do nacionalista), além das disputas com o campo da canção.

A partir da criação de um panorama da trajetória do Grupo Um foi possível perceber como aquele momento de maior aproximação com o Centro de Promoções Artísticas Lira Paulistana (entre os anos de 1980-1981) foi, justamente, o período em que o conjunto viveu o auge de sua carreira, com grande intensidade de atividade musical relacionada ao grupo. Além disso, a aproximação entre essas duas empreitadas se deu em um momento oportuno para ambas: o Lira buscava analisar e preencher sua programação, ainda em fase de planejamento, e o Grupo Um buscava um local para o lançamento de seu primeiro álbum prensado, Marcha sobre a cidade (1979). Assim, no início das atividades do Teatro Lira Paulistana, se constituiu uma relação muito forte entre o espaço e a música instrumental jazzística, justamente a partir dessa temporada de lançamento do primeiro disco da banda.

Após essas apresentações, ocorridas em fevereiro de 1980, a programação do Lira foi cada vez mais preenchida por grupos instrumentais do cenário jazzístico de São Paulo, como Pé-Ante-Pé, Freelarmônica, Divina Increnca, Pau Brasil, entre outros. Também os trabalhos de artistas vinculados ao selo exclusivamente instrumental Som da Gente passaram a se apresentar por lá. Segundo Chico Pardal (2016), “[...] na época, tinha o Som da Gente, que era um selo só de música instrumental, e começaram a se oferecer para lançar os discos lá com a gente. Então, no Lira, lançamos shows de quase todos da Som da Gente.”

Nesse movimento de aproximação com o Lira Paulistana, há outro elemento interessante e paradoxal: a questão da inclusão ou não do Grupo Um e de outros grupos de jazz instrumental no escopo do termo Vanguarda Paulista. Isso acontece pois um fator que parece ter sido determinante para a escolha do leque de artistas que foram incluídos pela crítica e pelos trabalhos acadêmicos nesse "gênero" é justamente a aproximação com o Centro de Promoções Artísticas Lira Paulistana. Ora, o Grupo Um praticamente iniciou a programação musical do Lira, ainda no início de 1980. O momento histórico das atividades, 
os locais de apresentação (além do próprio Lira, o MASP, o SESC e a Funarte também foram locais em que vários dos grupos da chamada Vanguarda Paulista buscaram dar vazão a seus trabalhos) e a retórica da música independente eram partilhados por esses músicos, ou seja: o Grupo Um e outros grupos instrumentais do jazz brasileiro atuaram sobre o mesmo cenário fonográfico, circularam pelos mesmos ambientes, carregaram para sua obra retóricas similares, mas acabaram, de um modo geral, ficando de fora do núcleo de artistas considerados os "principais" integrantes da Vanguarda Paulista (como Língua de Trapo, Premê, Arrigo Barnabé, Itamar Assumpção, entre muitos outros, todos relacionados a música cantada ${ }^{17}$ ), mesmo que carregassem elementos internos (na linguagem musical) daquilo que é comumente reconhecido como "música de vanguarda".

Meu propósito não é "incluir" o Grupo Um no referente dessa expressão criada pela imprensa, apenas demonstrar a rapidez com que se constroem movimentações, movimentos ou mesmo gêneros musicais, e a enorme fragilidade dessas construções, feitas a partir de um mecanismo de seleção que cria e cristaliza uma gama de representantes de determinada tradição musical, que passam então a ser considerados seus integrantes oficiais. Muitas vezes, esse procedimento é alicerçado em questões externas às próprias obras (haja vista que as propostas estéticas que conviviam nesse momento, mesmo as já referendadas pelo termo Vanguarda Paulista, são variadas e distintas), e distantes, também, das muitas proposições realizadas pelos atores envolvidos no processo. É interessante notar como, após algumas décadas de uso, o termo Vanguarda Paulista parece ter ficado realmente atrelado aos artistas vinculados ao formato canção. Na entrevista a mim concedida, enquanto comentava sobre a necessidade de se criar um selo instrumental para o Lira, Riba de Castro $^{18}$ (2016, grifos do autor) chega a ressaltar o seguinte:

Quando realizamos o contrato de distribuição com a gravadora Continental foi que tivemos a necessidade de criar um selo instrumental, pois a quantidade de grupos instrumentais era quase a mesma dos grupos que faziam parte da chamada Vanguarda Paulista.

Em um segundo momento, quando lhe perguntei diretamente se os grupos instrumentais faziam parte da chamada Vanguarda Paulista, Castro (2016) afirma:

Sem dúvida que faziam parte da vanguarda. Principalmente os grupos: Um, Pau Brasil, Pé ante Pé e o D’alma. Sempre que se fala ou se faz um evento

\footnotetext{
17 GUIMARÃES(1985), VAZ (1988), OLIVEIRA (1999), GHEZZI (2003), MURGEL (2005), FENERICK (2007), MACHADO (2007), SANTOS (2015) e MOTTA (2018).

${ }^{18}$ Em 2014, Ribamar de Castro, um dos gestores do Lira, lançou um livro com fotos, textos e vários materiais da época, além de um filme em formato de documentário sobre as atividades do espaço e sua relação com a vanguarda paulista, estão devidamente citados nas referências documentais deste artigo.
} 
sobre a vanguarda [paulista], os grupos instrumentais sempre estão presentes. E os discos de música instrumental sempre estiveram no Lira.

O exemplo de Riba de Castro (2016) parece ser elucidador: atualmente, ao se referir ao termo Vanguarda Paulista, a primeira ideia que "vem à cabeça" (inclusive na dos envolvidos no processo) são os grupos relacionados ao formato canção, estabelecendo praticamente um significado preestabelecido para a expressão. Se o termo não é utilizado automaticamente, mas sim após mínima reflexão, é possível perceber que há a intenção de expandir o leque de produções musicais abarcados por essa generalização. É preciso ter em mente que, por ser uma mediação social, a criação e difusão desses gêneros é sempre uma instância de reconhecimento e legitimação para as propostas musicais incluídas ou deixadas de fora do termo, daí sua relevância enquanto ferramenta de análise.

Se em 1980 e 1981 a crise que se instalava na economia e na indústria fonográfica brasileira parecia não afetar as produções realizadas pelo Grupo Um, já em 1982 e 1983 a inconstância do setor parece ter sido um dos principais fatores que dificultaram a existência do conjunto (mesmo com a parceria com o selo Lira Instrumental e com a turnê realizada na Europa). Devido à necessidade de sobrevivência, seus integrantes sempre participaram de outros projetos musicais. Todavia, durante os anos de 1980 e 1981 o universo de atuação desses músicos foi quase que exclusivamente relacionado às ações empreendidas pelo Grupo Um. A radicalização da crise da indústria fonográfica fez com que seus instrumentistas passassem, cada vez mais, a se focar novamente em trabalhos com outros músicos e, pela primeira vez, em suas trajetórias próprias.

Conforme pudemos observar, é possível perceber que, de qualquer forma - seja nos momentos em que o Grupo Um esteve mais ativo ou naquele anos em que sua atividade musical foi baixa -, a "busca pelo mecenas" é o elo aglutinador de sua trajetória, haja vista que sempre estiveram à procura de condições financeiras e materiais que tornassem possível o registro e a veiculação de suas experiências sonoras, tuteladas pelas ações e pesquisas dos irmãos Zé Eduardo e Lelo Nazário. Inclusive, quando a ideia de mecenas é utilizada pelo pianista, em matéria no jornal Folha de São Paulo, em 1982, o Grupo Um já havia viabilizado o lançamento de dois dos seus três discos, problematizando, assim, a situação que a música popular instrumental e o jazz brasileiro atravessavam naquele período em São Paulo. 


\section{Fontes}

ALMEIDA, Miguel. Muitos discos do Lira, uma ótima notícia. F. de São Paulo, São Paulo, 27 dez. 1982. Ilustrada, p. 17.

CASTRO, Riba de. Questionário respondido via internet, jun. 2016. Entrevista concedida ao autor deste artigo.

CASTRO, Riba de. Lira Paulistana: um delírio de porão. São Paulo: Ed. do Autor, 2014.

JAZZ: A volta do Grupo Um. Movimento, São Paulo, 5 out. 1981. Cultura.

LIRA Paulistana e a Vanguarda Paulista: um documentário musical. Direção: Riba de Castro. São Paulo: Busca Vida Filmes, 2014. DVD.

MUGGIATI, Roberto. Mauro Senise e o Grupo Um. Revista Manchete, Rio de Janeiro, abr. 1980.

NAZÁRIO, Lelo Nazário. Cotia/SP, Brasil, 3 jun. 2016. Entrevista concedida ao autor deste artigo.

NAZÁRIO, Zé Eduardo. 1980. Entrevista concedida a Aramis Millarch. (Acervo sonoro Aramis Millarch). Disponível em: <http://www.millarch.org/audio/z\%C3\%A9-eduardonaz\%C3\%A1rio>. Acesso em: 20 fev. 2020.

NAZÁRIO, Zé Eduardo. Questionário respondido via internet, jun/jul. 2016. Entrevista concedida ao autor deste artigo.

PROCURA-SE Mecenas. F. de São Paulo, São Paulo, 12 mar. 1982. Ilustrada, p. 33.

RIENZI, Francisco Teixeira. Rumo ao Grupo Um. A Tribuna, Santos, 28 fev. 1980.

SOUTO JÚNIOR, Wilson; PARDAL, Chico. São Paulo, Brasil, 4 jun. 2016. Entrevista concedida ao autor deste artigo.

\section{Discografia}

Grupo Um. Marcha sobre a cidade. [1979, LP Independente] Ed. remasterizada e aumentada. São Paulo: Editio Princeps, 2002. CD, digital, estéreo.

Grupo Um. Reflexões sobre a crise do desejo. [1981, LP Independente] Ed. remasterizada e aumentada. São Paulo: Editio Princeps, 2005. CD, digital, estéreo.

Grupo Um. A flor de plástico incinerada. [1982, LP Lira/Continental] Ed. remasterizada e aumentada. São Paulo: Editio Princeps, 2010. CD, digital, estéreo.

\section{Referências bibliográficas}

ADORNO, Theodor W. Filosofia da Nova Música. São Paulo: Perspectiva, 2011a.

ADORNO, Theodor W. Introdução à Sociologia da Música: doze preleções teóricas. São Paulo: Editora da UNESP, 2011b.

ADORNO, Theodor W. Teoria Estética. Tradução: Artur Mourão. Lisboa: Edições 70, 2012.

CAROCHA, Maika Lois. Pelos versos das canções: um estudo sobre o funcionamento da censura musical durante a ditadura militar brasileira (1964-1985). Dissertação (mestrado em História) - IFCS. Universidade Federal do Rio de Janeiro, Rio de Janeiro, 2007.

CASTRO, Igor Garcia. O lado B: a produção fonográfica independente brasileira. São Paulo: Annablume, 2010.

DIAS, Márcia Tosta. Os donos da voz: indústria fonográfica e mundialização da cultura. São Paulo: Boitempo, 2000. 
FENERICK, José Adriano. Façanha às próprias custas: a produção musical da vanguarda paulista (1979-2000). São Paulo: Annablume, 2007.

GHEZZI, Daniela Ribas. De um porão para o mundo: a vanguarda paulista e a produção independente de LP's através do selo Lira Paulistana nos anos 80 - um estudo dos campos fonográfico e musical. 2003. 264 p. Dissertação (Mestrado em Sociologia) - Instituto de Filosofia e Ciências Humanas, Universidade Estadual de Campinas, Campinas, 2003.

GUIMARÃES, Antônio Carlos Machado. A "nova música" popular de São Paulo. Dissertação (mestrado em Antropologia Instituto de Filosofia e Ciências Humanas, Universidade Estadual de Campinas, Campinas, 1985.

IANNI, Octavio. A sociedade global. Rio de Janeiro: Civilização Brasileira, 2005.

JAMESON, Fredric. Pós-modernismo: a lógica cultural do capitalismo tardio. São Paulo: Editora Ática, 1997.

MACHADO, Regina. A voz na canção popular brasileira - um estudo sobre a Vanguarda Paulista. Campinas, 2007. Dissertação de Mestrado em Música. Instituto de artes da Universidade Estadual de Campinas (UNICAMP), Campinas, 2007.

MENESES, Ulpiano T. Bezerra de. A história, cativa da memória? Para um mapeamento da memória no campo das Ciências Sociais. Revista IEB, n.34, p. 9-23, 1992.

MORELLI, Rita de Cássia Lahoz. Indústria fonográfica: um estudo antropológico. Campinas: Ed. UNICAMP, 2009,

MOTTA, Luísa Nemésio Toller. Se a obra é a soma das penas: um estudo feminista sobre as cantoras da Vanguarda Paulista. Dissertação (Processo de Criação Musical) Escola de Comunicações e Artes da Universidade de São Paulo, São Paulo, 2018.

MULLER, Daniel Gustavo Mingotti. Música instrumental e indústria fonográfica no Brasil: A experiência do selo Som da Gente. 2005. 201 f. Dissertação (Mestrado em Música) - Instituto de Artes, Universidade Estadual de Campinas, Campinas, 2005.

MURGEL, Ana Carolina Arruda de Toledo. Alice Ruiz, Alzira Espíndola, Tetê Espíndola e Ná Ozetti: produção musical feminina na vanguarda paulista. 2005. Dissertação (Mestrado em História) - Instituto de Filosofia e Ciências Humanas, Universidade Estadual de Campinas, Campinas, 2005.

NAPOLITANO, Marcos. 1964: História do Regime Militar Brasileiro. SP. Contexto, 2014 NAPOLITANO, Marcos. A arte engajada e seus públicos (1955-1968). Revista Estudos Históricos, Rio de Janeiro, n. 28, p. 103-124, 2001 a.

NAPOLITANO, Marcos. Cultura brasileira: utopia e massificação (1950-1980). São Paulo: Contexto, 2001b.

OLIVEIRA, Laerte Fernandes. Em um porão de São Paulo: o Lira Paulistana e a produção alternativa. 1999. 131f. Dissertação (Mestrado em Ciências Sociais) - Pontifícia Universidade Católica de São Paulo, São Paulo, 1999

ORTIZ, Renato. A moderna tradição brasileira: cultura brasileira e indústria cultural. São Paulo: Brasiliense, 1988.

ORTIZ, Renato. Mundialização e cultura. São Paulo: Ed. Brasiliense, 1994.

RUIZ, Renan Branco. "Procura-se Mecenas": Música independente e indústria fonográfica na trajetória artística do Grupo Um (1976-1984). Dissertação (Mestrado em História) Faculdade de Ciências Humanas e Sociais, Universidade Estadual Paulista "Julio de Mesquita Filho", Franca, 2017.

SANTOS, Anajá Souza. A canção oculta: um estudo sobre a vanguarda paulista. 2015. Dissertação (Mestrado em História) - Faculdade de Ciências Humanas e Sociais, Universidade Estadual Paulista, Franca, 2015.

SEIXAS, Jacy Alves de. Os tempos da memória: (des) continuidades e projeção. Uma reflexão (in) atual para a história? Revista Projeto História, São Paulo, n. 24, p. 43-63, jun. 2002. 
SEIXAS, Jacy Alves. Percursos da memória em terras de história: problemáticas atuais. In: BRESCIANI, Stella; NAXARA, Márcia Regina. Memória e (res)sentimento: indagações sobre uma questão sensível. Campinas: Ed. UNICAMP, 2001.

SIGNORI, Paulo Cesar. Tamba Trio: a trajetória histórica do grupo e análise de obras gravadas entre 1962-1964. 2009. 153 f. Dissertação (Mestrado em Música) - Instituto de Artes, Universidade Estadual de Campinas, Campinas, 2009.

VAZ, Gil Nuno. História da música independente. São Paulo: Brasiliense, 1988.

VICENTE, Eduardo. Da vitrola ao ipod: uma história da indústria fonográfica no Brasil. São Paulo: Alameda, 2014.

WILLIAMS, Raymond. Marxismo e literatura. Trad. Waltensir Dutra. Rio de Janeiro: Ed. Zahar, 1979.

WILLIAMS, Raymond. Política do modernismo: contra os novos conformistas. Trad. André Glaser. São Paulo: Ed. Unesp, 2011.

WILLIAMS, Raymond. Recursos da esperança: cultura, democracia, socialismo. São Paulo: Ed. UNESP, 2015. 